\title{
Article \\ Behavior of the Free Surface of Two-Phase Fluid Flow Near the Taphole in a Tank
}

\author{
Hyun-Sik Yoon * and Kyung-Min Park
}

Citation: Yoon, H.-S.; Park, K.-M. Behavior of the Free Surface of Two-Phase Fluid Flow Near the Taphole in a Tank. Symmetry 2021, 13, 875. https://doi.org/10.3390/ sym 13050875

Academic Editor: Iver H. Brevik

Received: 26 April 2021

Accepted: 11 May 2021

Published: 14 May 2021

Publisher's Note: MDPI stays neutral with regard to jurisdictional claims in published maps and institutional affiliations.

Copyright: (c) 2021 by the authors. Licensee MDPI, Basel, Switzerland. This article is an open access article distributed under the terms and conditions of the Creative Commons Attribution (CC BY) license (https:// creativecommons.org/licenses/by/ $4.0 /)$.
Department of Naval Architecture and Ocean Engineering, Pusan National University, 2, Busandaehak-ro 63beon-gil, Gumjeong-Gu, Busan 46241, Korea; kmpark0616@gatech.edu

* Correspondence: lesmodel@pusan.ac.kr; Tel.: +82-51-510-3685; Fax: +82-51-581-3718

\begin{abstract}
The present study numerically investigated the deformation of the free-surface of twophase fluid flow in a tank which is considered as a simplified blast furnace hearth. Actually, the fluids existing in a blast furnace hearth are gas, slag and hot metal from top to bottom. However, the present study considered only gas and cold molten iron in the tank. The porosity is considered as a substitute for void volume formed by the packed bed of the particles such as cokes. The single-phase flow and two-phase fluids flow without the porosity are analyzed for comparison. The porosity contributed the free surface to forming a viscous finger near the taphole. The axi-symmetry nature of the interface of two-phase fluids flow in the cylindrical tank is broken by viscous finger as the interface instability by the gas entrainment into taphole, which has been identified by the visualization of the free surface formation. The acceleration of the free surface falling velocity and the outflow near the taphole are associated by the viscous finger by the gas entrainment. The dimensionless gas break-through time is linear with respect to the porosity magnitude.
\end{abstract}

Keywords: free surface; two-phase fluid flow; viscous finger; porosity; taphole

\section{Introduction}

Iron-making furnaces contain multiphase materials such as gas, slag, molten iron, and cokes. This volume covers the inherent complex characteristics which involve the multiphase structure, high temperature, coupled heat and mass transfer, chemical reactions. Therefore, multiphase phenomena in the blast furnace have been widely studied in terms of the chemical reaction between different phases [1-5], the effect of porous medium [4-6], heat and mass transfer of multiphase flow [7-17], and optimized conditions to operate efficiently $[18,19]$.

The performance characteristics of blast furnaces are largely dependent on multiphase transport phenomena. For these reasons, Yagi [20] comprehensively reviewed the flow phenomena of multi-phase fluids which are composed of single-phase or multi-phase flows of gas, fine particles, liquid, and packed particles in the blast furnace. Later, Dong et al. [21] expanded on related studies that involved computational methods, numerical methods, and modelling. Successively, several studies have investigated transport phenomena in blast furnaces based on multi-phase flow [22-24]. In multiphase flows, the prediction of the void fraction is important in both stages of the preprocess and post-process of the experiments, resulting in different techniques [25-28] used for measuring the void fraction in multiphase flows being proposed.

During the transport phenomena in a hearth that has a taphole, an unexpected exit of blast gas occasionally occurs in the tapping process, causing severe fume emissions and splashing. This situation derives the various negative effects on the ironmaking process $[29,30]$.

In order to identify the reason for the unexpected splashy, He et al. [31] conducted an experiment on the internal flow in a blast furnace. They considered water instead of the hot metal to simulate and analyze the splash induced by the interaction of the air and water 
based on the principle of similarity. Their results show that the onset, evolution, and size of the splash are linked with the gas entrainment rather than wall roughness of the taphole, the cast rate, taphole blockage, or other factors. Especially, they reported that splashes are mainly linked to the inflow time and flow rate of air.

He et al. [31] pointed out that there are quite different characteristics of splashes between two blast furnaces, even though they considered the same chemistries of slag and molten iron. He et al. [32] extended the research of He et al. [31], and found that unexpected splashy taphole stream occurred, which results from blast gas entrainment into the taphole in the early stage of casting. They deduced that blast gas entrainment is strongly associated with the "viscous finger" resulting from the instability of the gas-liquid interface. Therefore, $\mathrm{He}$ et al. [32] focused on the relationship between blast gas and the viscous finger.

The viscous finger, which was considered to be the major source of the unexpected splash by He et al. [32], may form when a high-viscosity fluid is displaced by one with low viscosity in a porous medium. Instability of the interface between the fluids is developed, resulting in the finger-like patterns [33]. The viscous finger has received much attention in the steel industry, as well as other fields, due to its interesting flow features and practical importance. Hill et al. [34] studied the viscous finger which occurs in cylindrical cisterns during the refining of raw sugar. Additionally, the phenomenon in rock with a porous medium has been studied by Tabeling et al. [35].

He et al. [30] carried out an experiment to increase understanding of the mechanisms underpinning the phenomenon of the early release of blast gas in blast furnace tapping operations. Particularly, they focused on determining the likelihood that viscous fingering is the main reason for this event. In their experiment, the blast furnace model was packed with glass beads and the fluids used in the experiment were considered as air, mineral oil and $\mathrm{ZnCl2}$, instead of gas, slag, and iron. Their experiment showed viscous fingering, which induced the premature release of gas. Additionally, they reported that the early release of blast gas occurs with increasing a draining rate and the condition of packed bed heterogeneity.

As described above, the appearance of viscous fingers at the interface of fluids in a blast furnace is important for the iron-making operations. Thus, the present paper numerically simulates two-phase fluids flow in a tank as a simplified blast furnace hearth. In addition, the porosity has been considered as the packed bed of the particles, including cokes. Generally, the porous medium is used to replace the particle bed, which reflects the two effects of porosity and the exerting forces on the fluids in the blast furnace simultaneously. However, as the initial stage of the research for the complex multi-phase fluid flow in the blast furnace, first, the present study focused on the porosity effect on the interface of two-phase fluid flow in a tank.

The main purpose of the present study was to investigate the effects of gas entrainment into the taphole and the porosity on the deformation of the gas-liquid interface. Based on the authors' literature survey, it was hard to find that studies using a numerical approach, especially, considering the gas and liquid in a tank with a taphole to investigate the net effect of gas entrainment into the taphole on the deformation of the gas-liquid interface. Thus, to clearly identify the net effect of the gas on interface formations, such as viscous fingers, the present study considered only gas and liquid in a tank with a taphole. In addition, the present study originally explored the effect of porosity on the deformation of the interface of the two-phase fluids and gas entrainment into the taphole by considering the wide range of porosity.

In order to systematically analyze the effects of the porosity and the two-phase fluids on the formation of the interface of two-phase fluid flow near the taphole, the present study additionally simulated single-phase flow to compare the two-phase flow. Additionally, two-phase flow without porosity has been simulated to find the effect of porosity on the interface of two-phase fluids. The interface formation will be visualized to investigate the effect of gas and porosity on the interface instability, such as a symmetry breaking. 
Especially, the appearance of the taphole in the tank plays a key role on the interface of two-phase fluid flow. Therefore, the contribution of the taphole has been evaluated in terms of the viscous finger and the dimensionless gas break-through time.

\section{Governing Equations and Mathematical Formulation}

\subsection{Governing Equations of Fluid Flow}

The STAR-CCM+ [36] computational fluid dynamics (CFD) package was adopted for the present numerical simulations. The continuity equation, the Navier-Stokes equations, and the volume of fraction (VOF) equation govern the three-dimensional two-phase flow as the present problem. The Reynolds-averaged Navier-Stokes equations can be written in Cartesian tensor form as

$$
\begin{gathered}
\frac{\partial \varepsilon u_{i}}{\partial x_{i}}=0 \\
\frac{\partial}{\partial t}\left(\varepsilon \rho u_{i}\right)+\frac{\partial}{\partial x_{j}}\left(\varepsilon \rho u_{i} u_{j}\right)=-\frac{\partial \varepsilon p}{\partial x_{i}}+\frac{\partial}{\partial x_{j}}\left[\varepsilon \mu\left(\frac{\partial u_{i}}{\partial x_{j}}+\frac{\partial u_{j}}{\partial x_{i}}\right)\right]+\frac{\partial}{\partial x_{j}}\left(-\varepsilon \rho \overline{u_{i}^{\prime} u_{j}^{\prime}}\right)+\varepsilon \rho g_{i}
\end{gathered}
$$

where $x_{i}$ are Cartesian coordinates, $\varepsilon$ is porosity, $u_{i}$ are the corresponding velocity components, $p$ is pressure, $\rho$ is fluid density, $\mu$ is fluid viscosity, and $g$ is the gravity. Additionally, $-\rho \overline{u_{i}^{\prime} u^{\prime}} j$ is the Reynolds stress term which has been closed using the realizable $k-\varepsilon$ turbulence model [37].

The resistance of the porous media can be realized by adding the source term in the momentum equation. If the porous region is assumed to be homogeneous and isotropic, isotropic resistance can be determined using the Ergun equation [38]. In the porous region, the theoretical pressure drop per unit length was determined using the Forchheimer equation [39], expressed as Equation (3).

$$
-\frac{\Delta P}{L}=\left(P_{i} u_{o}^{2}+P_{v} u_{o}\right)
$$

The Ergun equation [38] is popularly utilized in porous media flow. A semi-empirical correlation can be applied over a wide Reynolds number range for various packing types.

$$
-\frac{\Delta P}{L}=\frac{150 \mu(1-\varepsilon)^{2} u_{o}}{\varepsilon^{3} d_{p}^{2}}+\frac{1.75 \rho(1-\varepsilon) u_{o}^{2}}{\varepsilon^{3} d_{p}}
$$

where $u_{0}$ is the superficial velocity through the porous region, $d_{p}$ is the coke particle diameter $(\mathrm{m})$ and $P_{i}, P_{v}$ are coefficient defining the porous resistance, known as the inertial resistance and viscous resistance, respectively.

Generally, the porous medium is used to replace the particle bed, which simultaneously reflects the two effects of porosity and exerting forces on the fluids in a blast furnace. However, the present study focused on the porosity effect on the interface of two-phase fluid flow near the taphole in a tank. Thus, the porous resistances were neglected.

The free surface of two-phase flow is tracked by using the VOF method, which is used by most commercial codes. The distribution of two-phase fluids in the computational domain is governed by the following transport equation.

$$
\frac{\partial Q_{\delta}}{\partial t}+u_{i} \frac{\partial Q_{\delta}}{\partial x_{i}}=0
$$

where $Q_{\delta}$ is the volume fraction in cells.

First, each momentum equation corresponding the phase is computed, sharing the resulting velocity among the phases [40]. The diffusion term is spatially discretized by the second-order central differencing scheme. The convection term is spatially discretized by the second-order upwind scheme. For the temporal discretization, the first-order backward implicit scheme is utilized for the time derivative terms. A SIMPLE-type segregated algorithm is used the solution procedure. 


\subsection{Computational Domain and Boundary Conditions}

The unstable interface of two-phase fluids and viscous fingers are expected to take place in the hearth of the blast furnace. Therefore, the hearth was chosen as the computational domain, which was formed by a cylindrical shape. The computational domain was scaled down and assumed to be the hearth part of the blast furnace in the present work. The aim of the present study was mainly to investigate the deformation of the interface according to porosity in the vicinity of the taphole; therefore, the scale-down method was reasonable and is often chosen in other studies [41].

The computational domain and relative boundary conditions are shown in Figure 1a, where the dimensions of the tank were $1 \mathrm{~m}$ in diameter $\left(D_{h}\right)$ and $1.5 \mathrm{~m}$ in height $\left(H_{h}\right)$. The taphole diameter $\left(D_{t}\right)$, height $\left(H_{t}\right)$ and length $\left(L_{t}\right)$ were $0.05,0.5$ and $0.3 \mathrm{~m}$, respectively. The taphole was tilted at an angle of $5^{\circ}$ from the bottom. The tank was filled with molten iron initially and only air was supplied from the inlet. Porosity $(\varepsilon)$, which represents the void fraction by the packed bed, was considered to be from 0.2 to 1.0 to investigate the effects. The inlet and outlet boundary conditions were imposed as pressure conditions with a gauge pressure of $450 \mathrm{kPa}$ and atmospheric pressure, respectively. The remaining boundaries were imposed as a no-slip conditions. The viscosity and density of the fluids were set as $\rho_{m i}=7000 \mathrm{~kg} / \mathrm{m}^{3}, \eta_{m i}=7.15 \times 10^{-03} \mathrm{~Pa} \cdot \mathrm{s}, \rho_{\text {air }}=1.18 \mathrm{~kg} / \mathrm{m}^{3}, \eta_{\text {air }}=1.85 \times 10^{-05} \mathrm{~Pa} \cdot \mathrm{s}$ where the subscripts of $m i$ and air denote a molten iron and an air. The conditions for calculation are shown in Table 1.

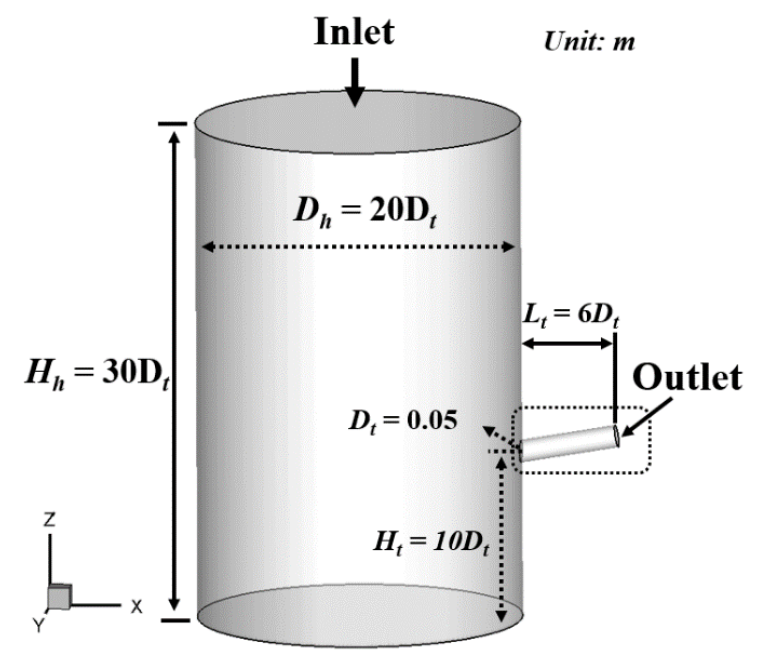

(a)

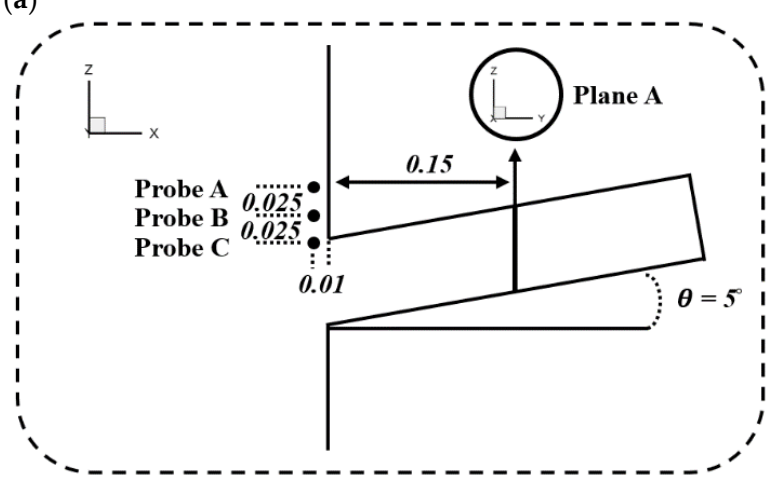

(b)

Figure 1. (a) The schematic of the computational domain and (b) the locations of the probes to monitor the velocity variation with time. 
Table 1. Conditions for calculation: parameters of the tank and fluid properties.

\begin{tabular}{cc}
\hline Variable & Value \\
\hline Hearth diameter, $D_{h}(\mathrm{~m})$ & 1 \\
Hearth height, $H_{h}(\mathrm{~m})$ & 1.5 \\
Taphole diameter, $D_{t}(\mathrm{~m})$ & 0.05 \\
Taphole height, $H_{t}(\mathrm{~m})$ & 0.5 \\
Taphole length, $L_{t}(\mathrm{~m})$ & 0.3 \\
Tilting angle of taphole, $\left({ }^{\circ}\right)$ & 5 \\
Molten iron density, $\rho_{m i}\left(\mathrm{~kg} / \mathrm{m}^{3}\right)$ & 7000 \\
Molten iron viscosity, $\eta_{m i}(\mathrm{~Pa} \cdot \mathrm{s})$ & $7.15 \times 10^{-3}$ \\
Air density, $\rho_{\text {air }}\left(\mathrm{kg} / \mathrm{m}^{3}\right)$ & 1.18 \\
Air viscosity, $\eta_{\text {air }}(\mathrm{Pa} \cdot \mathrm{s})$ & $1.85 \times 10^{-5}$ \\
Pressure drop, $\mathrm{P}_{\text {inlet }}-\mathrm{P}_{\text {outlet }}(\mathrm{kPa})$ & 450 \\
Porosity, $\varepsilon$ & $0.2,0.3,0.4,0.6,0.8,1.0$ \\
\hline
\end{tabular}

Figure $1 \mathrm{~b}$ marks the probes and a plane near the taphole, which were later used to trace the flow quantities.

A grid system for numerical analysis is shown in Figure 2 where the grid was created by cut-cell grid method in STAR-CCM+ [36]. The grid was denser near the moving interface of the two-phase fluids to capture the deformation of the free surface. To quantitatively verify the grid systems, three different grid numbers were considered with $5 \times 10^{5}$ (coarse), $1.8 \times 10^{6}$ (medium), and $2.1 \times 10^{6}$ (fine). According to the results of grid dependency test, the dependence of the free surface deformation on the grid was almost negligible, and the velocity and pressure in the vicinity of the taphole had a very small discrepancy of less than $1 \%$ for different grid systems. Therefore, this study used the medium grid system for the efficiency of computation.

\subsection{Validation}

As mentioned in the Introduction, it is hard to find studies similar to the present study which simulate the free surface problem in the blast furnace. Based on a literature survey, Shao and Saxen [41] studied the transient flow behavior of iron and slag in the taphole of a blast furnace by applying a VOF-based CFD model. Although their main focus was not on flow patterns in the hearth but taphole flow patterns during tapping, their study is quite suitable to validate the present numerical methods handling the interface of the two-phase flow. Therefore, we followed the conditions of Shao and Saxen [41] for the validation. The dimensions of the liquid reservoir were $0.8 \mathrm{~m}$ in length, $0.1 \mathrm{~m}$ in breadth, and $0.28 \mathrm{~m}$ in height. The slag-iron interface was fairly horizontal at some distance from the taphole. The taphole diameter, length, and height were $0.04,0.8$, and $0.12 \mathrm{~m}$, respectively. The taphole was located at a small distance above the bottom of the liquid reservoir (i.e., height $=0.12 \mathrm{~m}$ ), because this study focused on the flow conditions near the taphole. Slag was taken into the liquid reservoir by a mass flow rate of $22.4 \mathrm{~kg} / \mathrm{s}$, and atmospheric pressure was set at the taphole outlet. The total number of grids was more than 250,000. The grid was densified close to the taphole, where the liquid velocities varied drastically. 


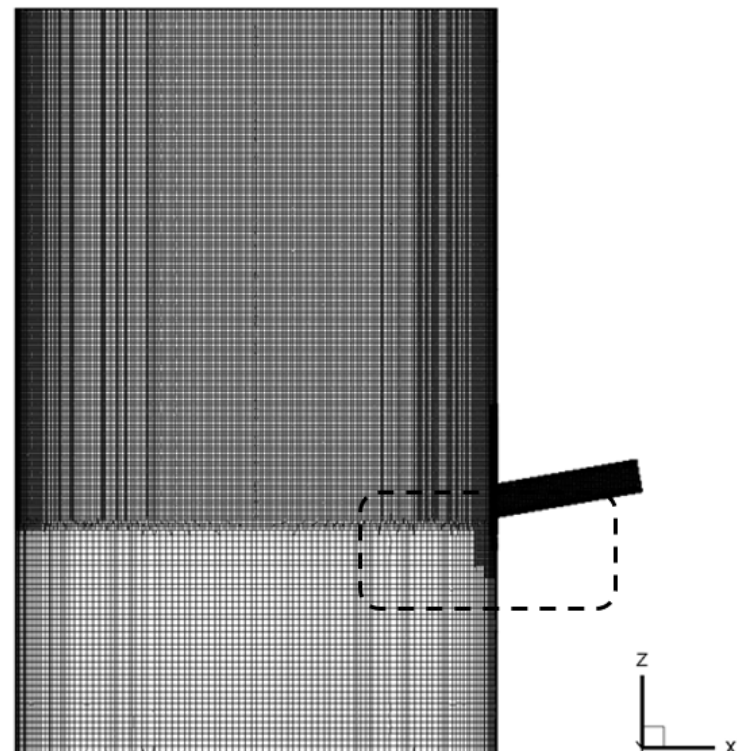

(a)

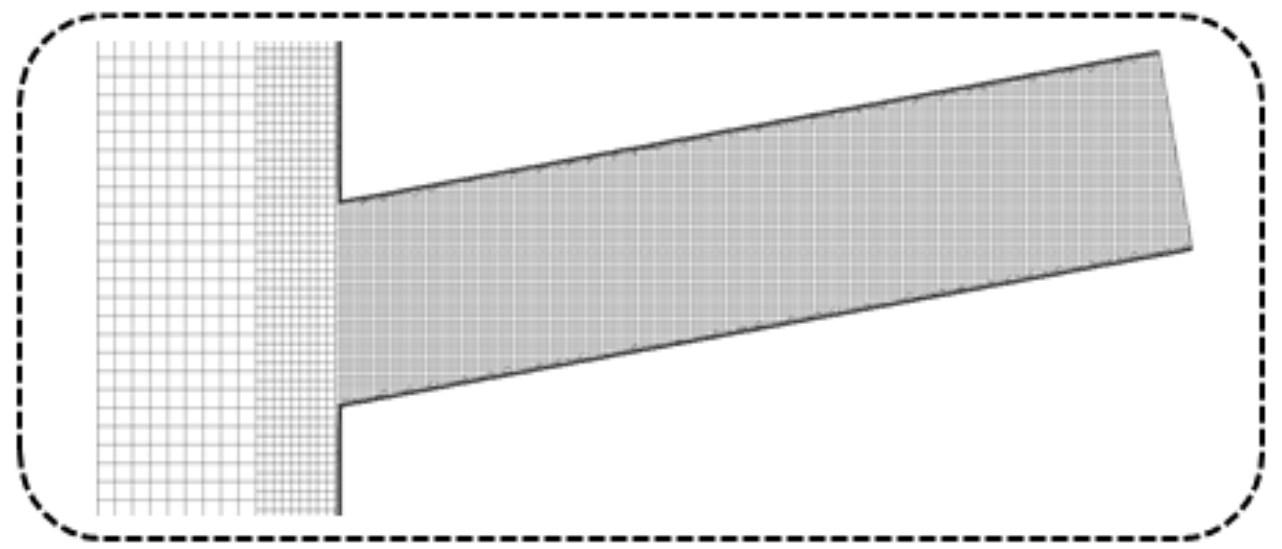

(b)

Figure 2. Numerical grids of (a) the blast furnace and (b) the taphole.

Figure 3a shows the free surface in the tank corresponding to time. The results represent the free surface tilt down (declination) and tilt up (inclination) in the vicinity of the taphole. This situation is the feature that occurred in the actual tapping process. In addition, for the stratified flow in the taphole, the time sequence of the volume fraction of fluids (iron, slag) is compared in Figure 3b. The time-dependent behavior of the free surface of the present results was similar to Shao and Saxen [41].

Quantitative comparisons between the present results and those of Shao and Saxen [18] were carried out for the time histories of mass flow rate for iron and slag. Figure 4 shows the favorable comparison with Shao and Saxen's [41] results, even the difference which appeared in the initial tapping period. Consequently, the present results are reasonably comparable to the previous results reported by Shao and Saxen [41]. 


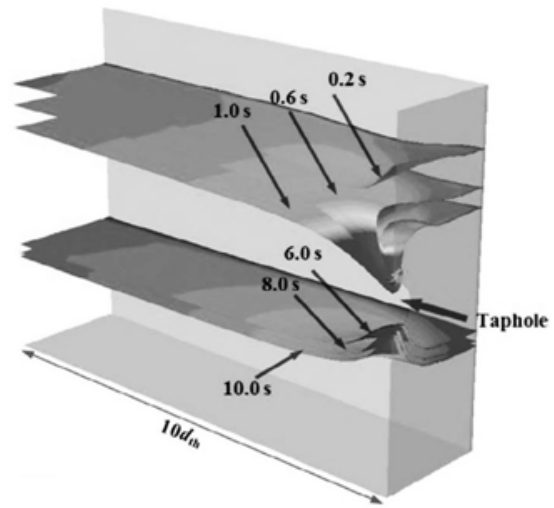

(a)

$t=2.0 \mathrm{~s}$

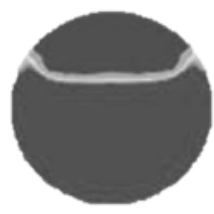

$t=3.0 \mathrm{~s}$

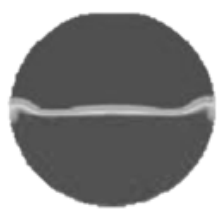

$t=4.0 \mathrm{~s}$

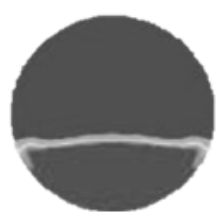

$t=5.0 \mathrm{~s}$

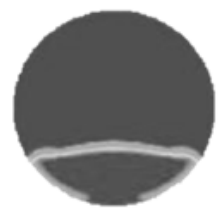

(b)

Figure 3. Comparison of slag-iron interfaces (a) during tapping and (b) at an entrance of the taphole.

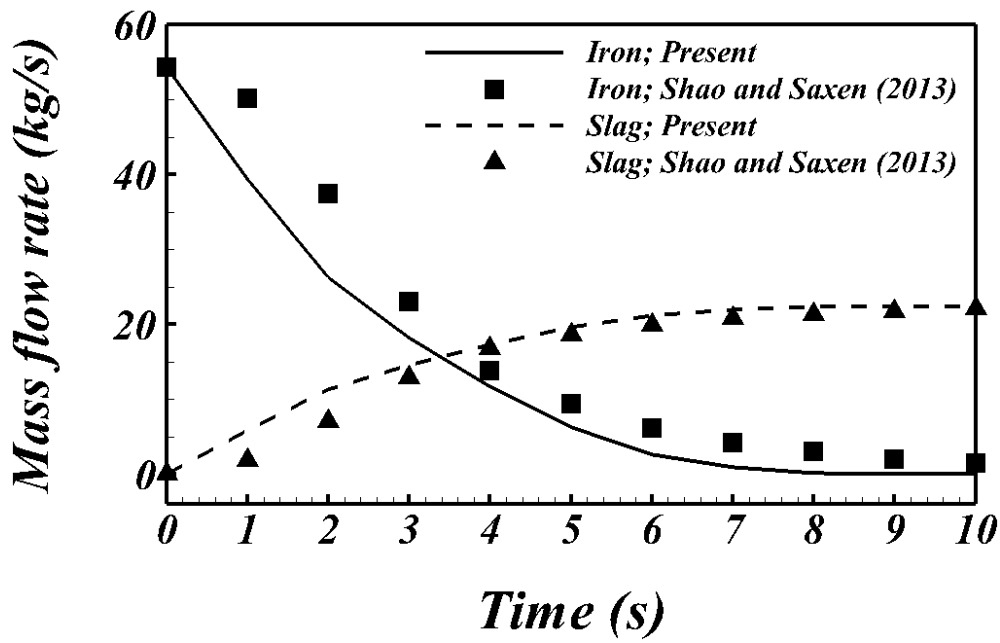

Figure 4. Comparison of mass flow rate of iron and slag during the short-term tapping operation. 


\section{Results and Discussion}

\subsection{Interface Behavior with and without Porosity}

The typical deformation of the free surface for two-phase flows with and without porosity is shown in Figure 5. The porosity in the computational model was $\varepsilon=0.36$, corresponding to a real hearth. Both cases showed the same behavior of the free surface, which retained the initial flat formation without any deformation before it came close to the taphole. In particular, in the case of porosity, when the free surface was close to the taphole, fluids were sucked into the taphole with high velocity, forming relatively lower pressure in the region near the taphole. Then, the free surface deformed and inclined into a low-pressure region in the vicinity of the taphole, as shown in Figure $5 c, d$ for the porosity case. However, at the same time, corresponding to $t=8.0 \mathrm{~s}$, the free surface without porosity was far from the taphole, which could be more clearly identified by the free surface descending position and velocity.

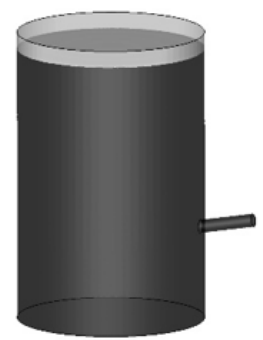

(a) $\mathrm{t}=2.0 \mathrm{~s}$

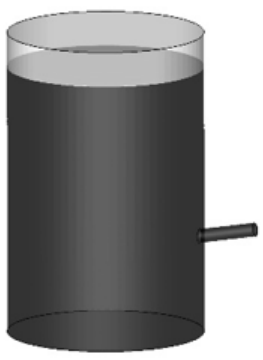

(b) $\mathrm{t}=4.0 \mathrm{~s}$

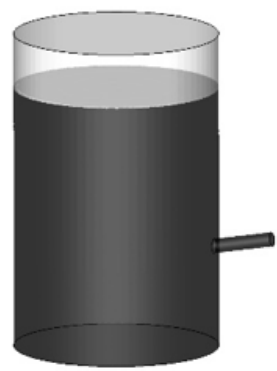

(c) $\mathrm{t}=6.0 \mathrm{~s}$

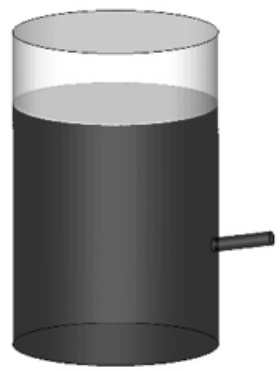

(d) $\mathrm{t}=8.0 \mathrm{~s}$
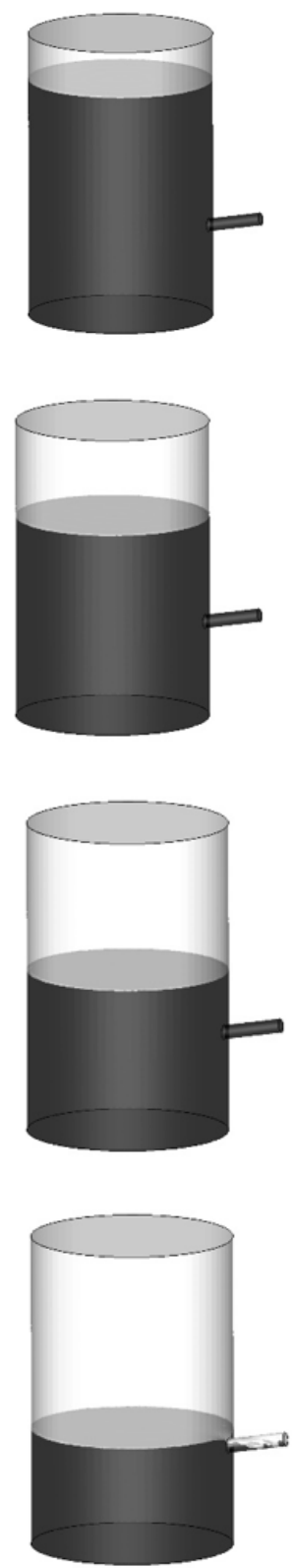

Figure 5. Time sequences of the remaining molten iron at regular intervals from $2.0 \mathrm{~s}$ to $8.0 \mathrm{~s}$ of the tapping process without porosity (left column) and with porosity (right column). 
To clearly identify the dependence of the free surface on porosity, the time sequence of the free surface in the two-dimensional $(x-z)$ plane, which cuts across the center of the taphole, was examined, as shown in Figure 6.

The free surface under the condition of the two-phase flow without porosity descended from the initial position, retained an almost-flat formation, and gradually leant toward the taphole, as shown in Figure 6a-d. As a result, the formation of the free surface followed a smooth parabolic profile with the defection point at the taphole. The gas- and liquidphase fluids flowed into the taphole together, and eventually air occupied the inside of the taphole duct.

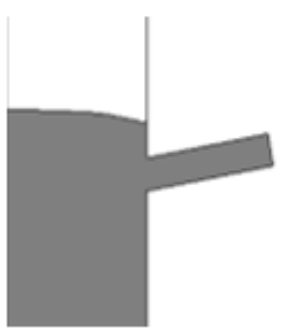

(a)

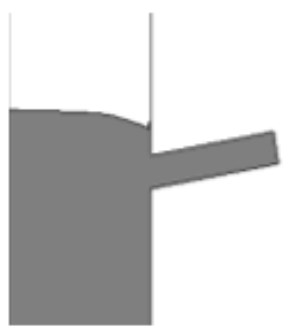

(b)

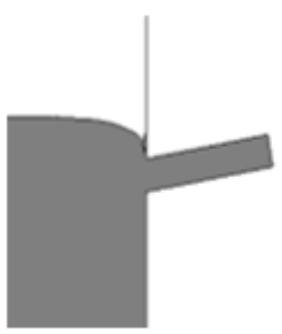

(c)

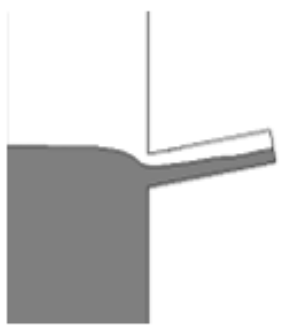

(d)

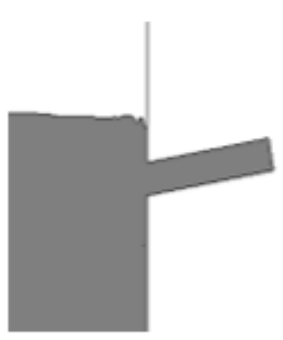

(e)

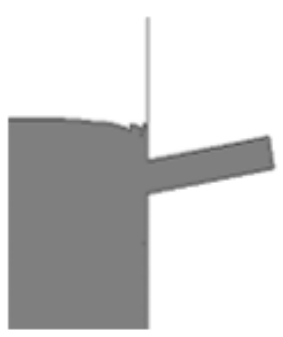

(f)

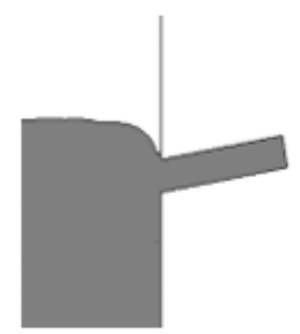

(g)

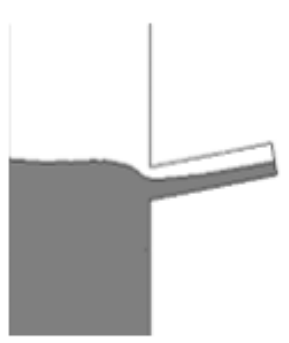

(h)

Figure 6. Comparison of free surface shapes $(\mathbf{a}-\mathbf{d})$ with porosity and (e-h) without porosity according to location around the taphole.

In contrast to the case without porosity, the free surface under the condition with porosity revealed a discontinuous formation with sharp branches as it approaches the taphole, as shown in Figure 6e-h. At the same time, the free surface with porosity descended faster than that without porosity, which could be clarified by the mean position of the 
free surface over time, as shown in Figure 7. Here, the mean position was achieved by surface-averaging the free surface.

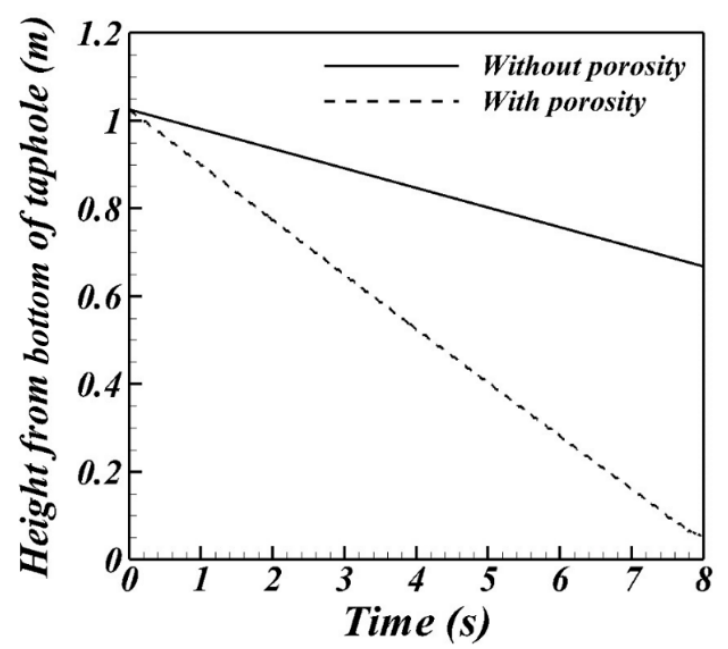

Figure 7. Mean position of the free surface versus the time for the cases with and without porosity.

To clearly observe the deformation of the free surface with porosity, the region containing the discontinuous formation of the free surface is magnified in Figure 8. As observed in Figure 6, when the free surface was close to the taphole, it was successively spitted, which can be observed in Figure 8. This spitted formation of the free surface is comparable to the viscous finger which was previously presented by the experimental results of He et al. [30]. Saffman and Taylor [33] derived the first theory, Saffman and Taylor instability, and performed simulated experiments in a Hele-Shaw cell, thereby showing viscous fingering.

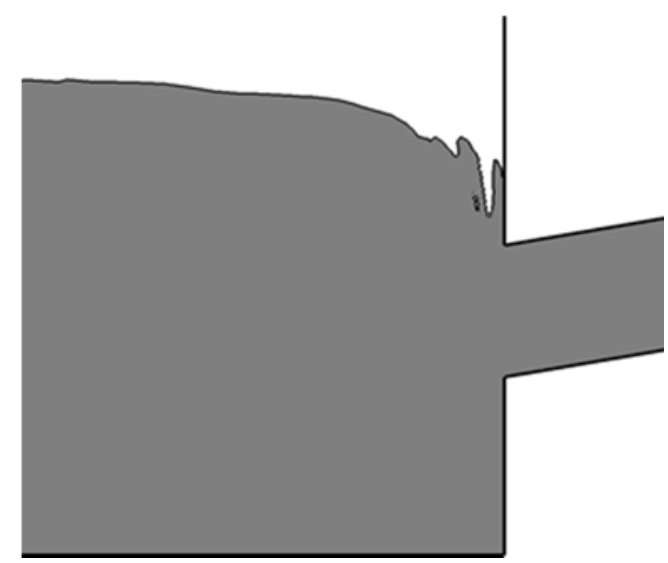

Figure 8. The formation of the free surface near the taphole.

The operating conditions considered in this study are applicable to the case in the occurrence of viscous fingering. Namely, in the course of hearth drainage, the liquid phase is displaced by the less viscous gas phase. Therefore, the present formation of the unstable free surface between two fluids with porosity in the blast furnace is comparable to viscous fingering.

In addition, He et al. [32] considered free surface instability in the blast furnace, showing the appearance of the viscous fingers as the unstable gas-liquid interface. Additionally, they reported that unexpected gas release is related to the high drainage velocity. Later, $\mathrm{He}$ et al. [7] presented viscous finger formation due to the unstable gas-liquid interface near the taphole. Consequently, we note that the viscous fingers help increase the free surface descent and the velocity of the blast gas entrained into the taphole. 
These results are consistent with the findings of the present study, as shown in Figures 5 and 7, where the free surface with porosity descended faster than in the case without porosity and showed unstable formation relevant to viscous fingering.

Figure 9 shows the time histories of the plane-averaged velocity for single-phase flow, and two-phase flows with and without porosity at the center of the cross-sectional plane A at the taphole marked in Figure 1b. In single-phase flow, the magnitude of the velocity is about constant, which results in a nearly steady state problem under this condition. In contrast to the single-phase flow case, both two-phase flows show time-dependent behavior that contains a rapid increase in the velocity due to gas entrainment, regardless of porosity, as shown in Figure 9a. However, two cases for the two-phase flow exhibit different trends along the time. The case without porosity shows that the value of the velocity monotonically decreases without fluctuation before a sudden increase, as shown in Figure $9 \mathrm{~b}$. Otherwise, velocity under the condition with porosity has an oscillatory period before the sudden increase, as shown in Figure 9c. It might be explained that this oscillation of velocity is derived by the viscous fingers, which originated on the unstable free surface.

The oscillation of velocity becomes significant when the gas starts to be entrained into the taphole. There is some time between the initial entraining and the next entraining. It can be considered that this duration is derived by the viscous fingers which suddenly extend downward with the branches. Some branches reach the taphole earlier than others. Therefore, the case with porosity reveals several impulsive behaviors, with velocity which is an order of magnitude higher than that of the constant velocity period in Figure 9a. This result is consistent with results reported by He et al. [9]. This early appearance of the high entraining velocity with porosity resulted in a faster descent of the free surface than the case without porosity, as shown in Figure 7.

\subsection{Effect of the Porosity Magnitude}

To investigate the effect of the porosity magnitude on two-phase fluid flow and the interface, different magnitudes of porosity in the range of $0.2 \leq \varepsilon \leq 1$ were considered. Figure 10 exhibits formations of the free surface for different porosity magnitudes at the same instant when the gas started to drain into the taphole for $\varepsilon=0.2$, which was the smallest porosity value considered in this study. In contrast to $\varepsilon=0.2$, the free surface for other porosity magnitudes did not reach the taphole. As shown in Figure 10, the distance between the free surface and the taphole increased as the porosity magnitude increased.

The mean position of the free surface $\left(P_{M F}\right)$ over time for different porosity magnitudes is plotted in Figure 11, where the origin of the position is the bottom of the taphole. Here, the time history of the mean position of the free surface is considered before the gas is initially entrained into the taphole. As mentioned in Figure 10, as the porosity magnitude decreased, the descent of the free surface increased, leading to earlier gas draining. In general, regardless of the porosity magnitude, the time history of the mean position of the free surface followed a linear profile.

However, the slope was strongly dependent on porosity magnitude. This slope can be considered the mean descending velocity of the free surface $\left(V_{M F}\right)$ which is presented in Figure 12. In the range of the small porosity magnitudes for $\varepsilon=0.2 \sim 0.4$, the gradient rapidly augments. As the porosity magnitude continuously increases from $\varepsilon=0.4$ to 1 , the increasing rate of the gradient becomes smaller. Thus, the mean position of the free surface can be simply approximated by a function of the porosity magnitude as follows: $P_{M F} \approx V_{M F}(\varepsilon) \cdot t$, where $V_{M F}(\varepsilon)$ are approximated by $V_{M F}(\varepsilon) \approx V_{M F, \varepsilon=1} \frac{1}{\varepsilon}$. The coefficient $V_{M F, \varepsilon=1}$ in $V_{M F}(\varepsilon)$ corresponds to the mean descending velocity of the free surface for $\varepsilon=1$. 


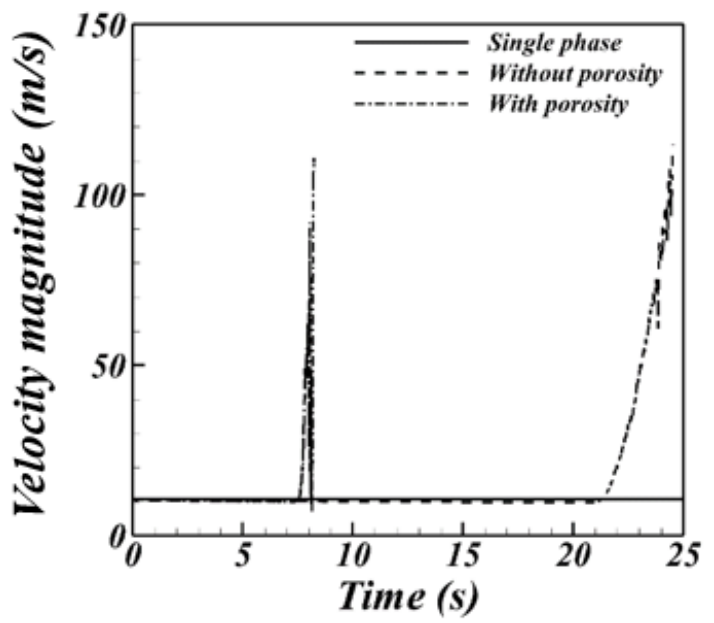

(a)

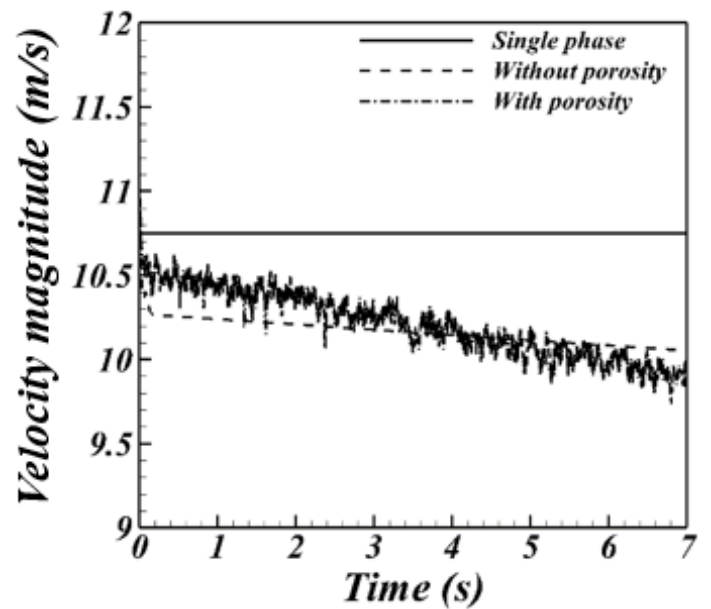

(b)

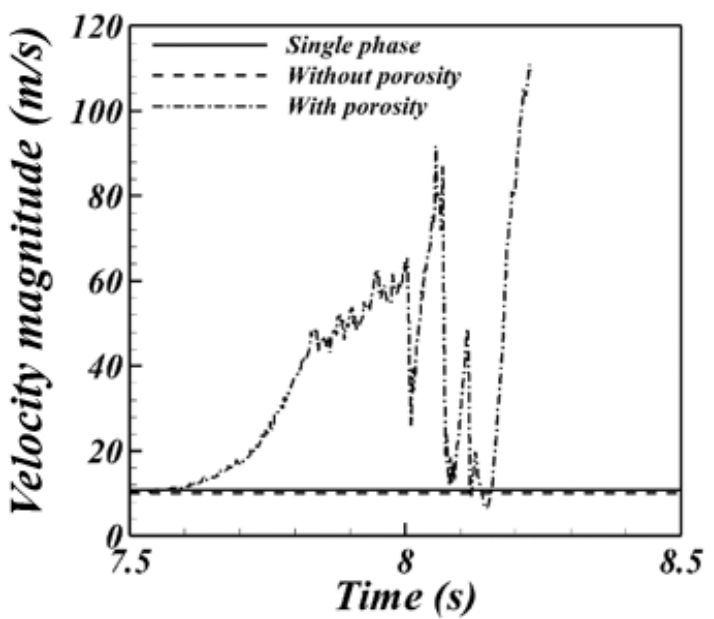

(c)

Figure 9. Time histories of averaged velocity magnitude over plane A until the gas was entrained into the taphole for: (a) both cases with and without porosity; (b) enlarged region before gas is entrained into the taphole with and without porosity; and (c) enlarged region after gas is entrained into the taphole with porosity. 


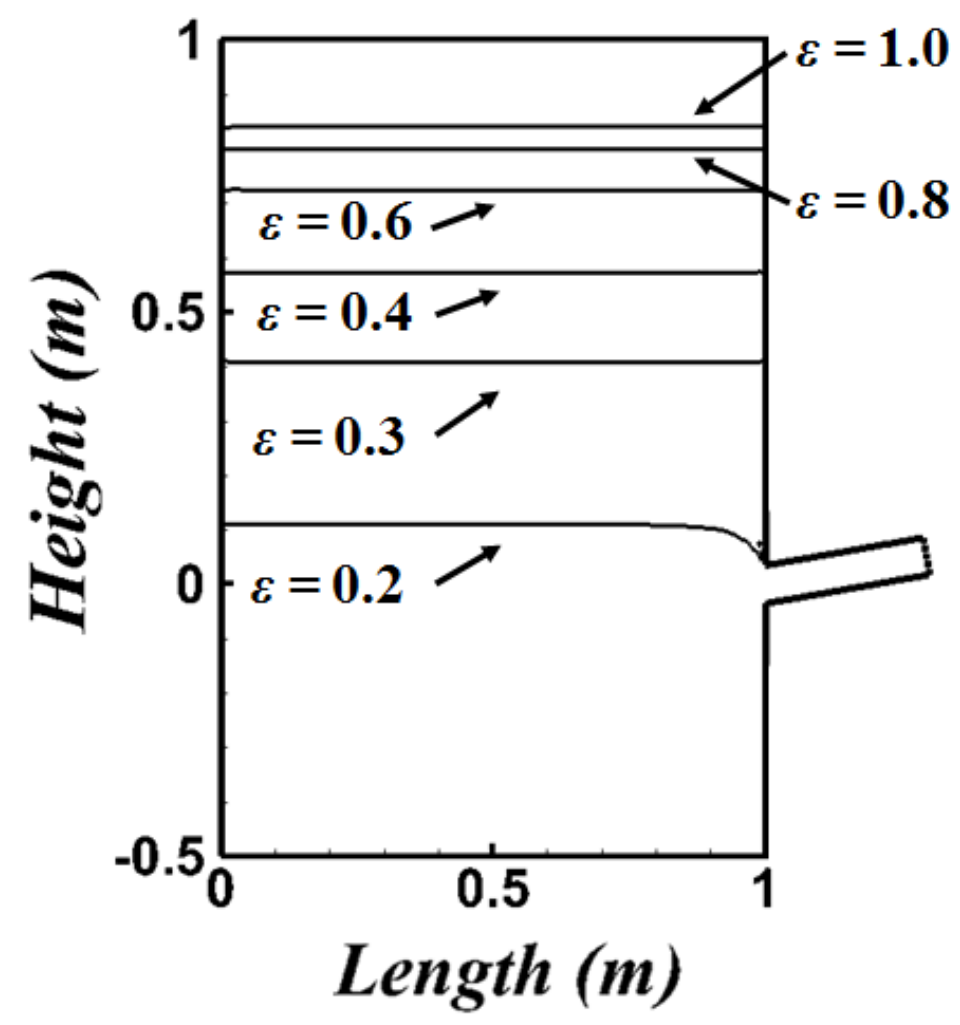

Figure 10. Comparison of height of free surface at same instance for six different porosities $(\varepsilon)$.

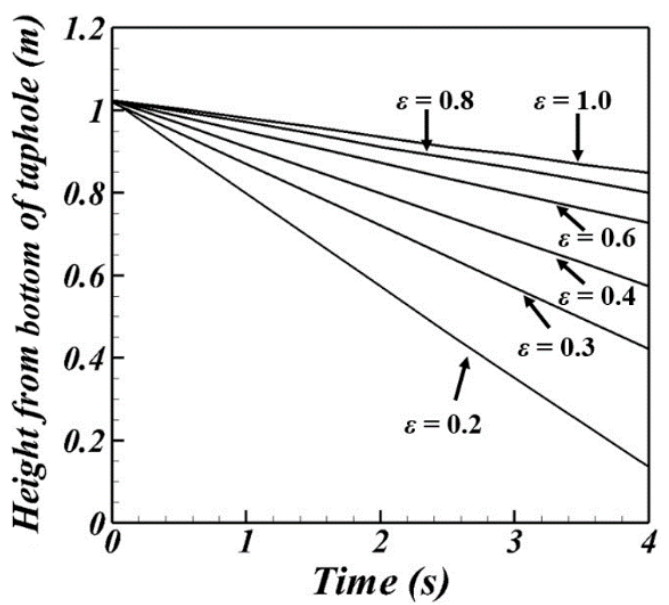

Figure 11. Comparison of time histories of mean position of the free surface for six different porosities $(\varepsilon)$.

Figure 13 shows time histories of the mass flow rates for different porosity magnitudes. All cases showed the same time-dependent behavior of the mass flow rate. As time passes, the mass flow rate slightly decreased and then suddenly diminished. The slow reduction in the mass flow rate was induced by the decrease in the liquid head, which corresponded to pressure due to the liquid's weight. 


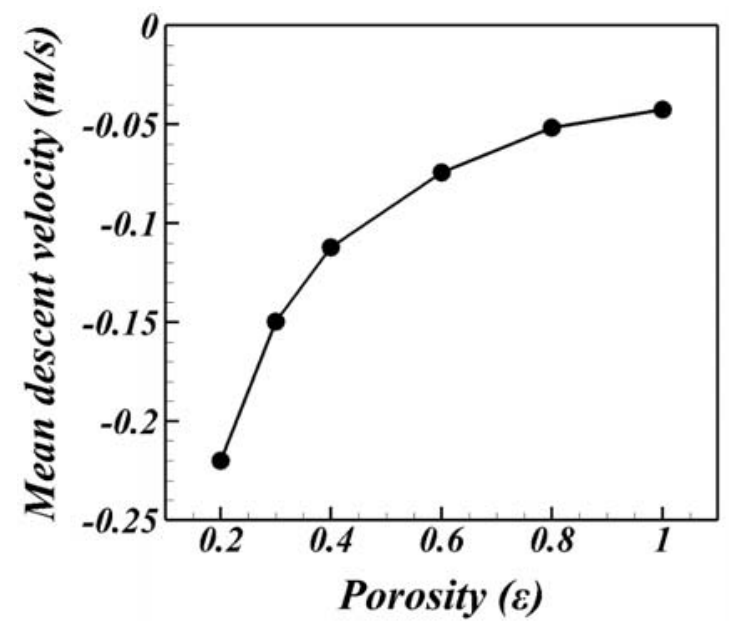

Figure 12. Mean descent velocity of free surface for six different porosities $(\varepsilon)$.

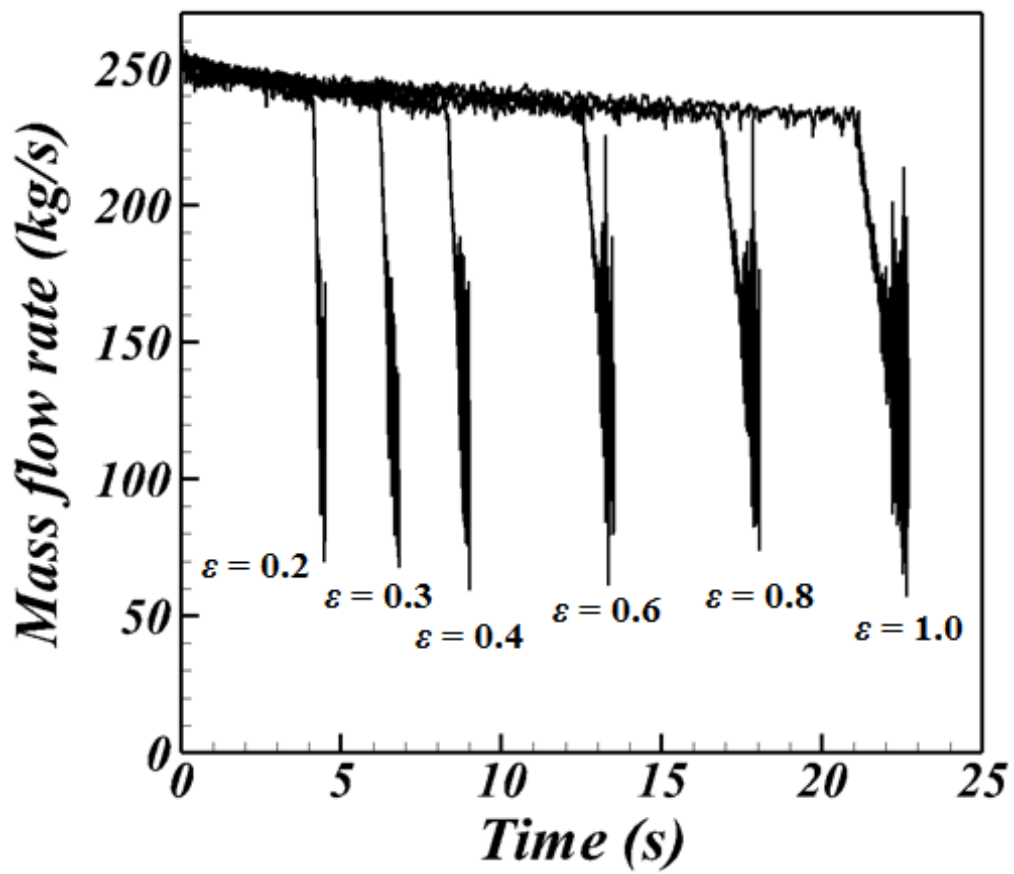

Figure 13. Time histories of mass flow rate for six different porosities $(\varepsilon)$.

The sudden drop in the mass flow rate was initiated by the initial inflow of the gas into the taphole. The mass flow rate is defined by the product of the density, the surface area, and the velocity normal to the surface. Thus, this mass flow rate is comparable to velocity at the probes shown in Figure 14, and the densities of the gas and the liquid metal. The density of gas is much lower than that of liquid metal, by about four orders of magnitude. However, the velocity of gas for the drain is two orders of magnitude larger than that of the liquid metal, as shown in Figure 14. Eventually, when the gas flows into the taphole, the mass flow rate is about two orders of magnitude smaller than that of the liquid metal. 


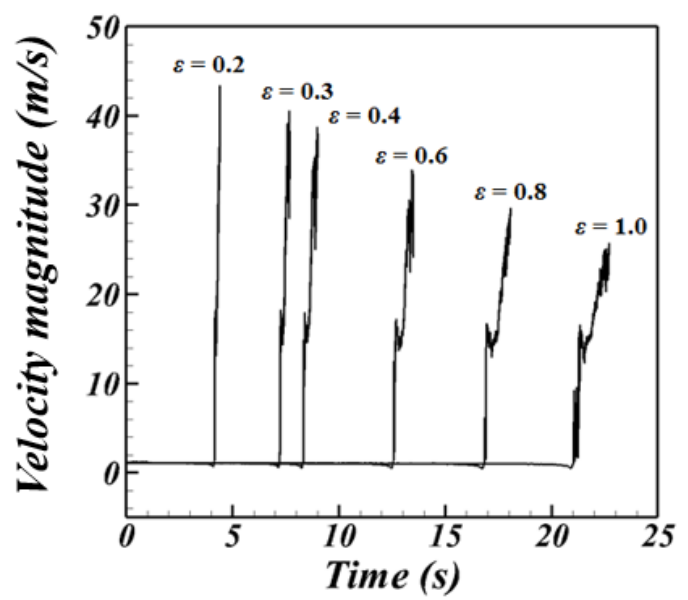

(a)

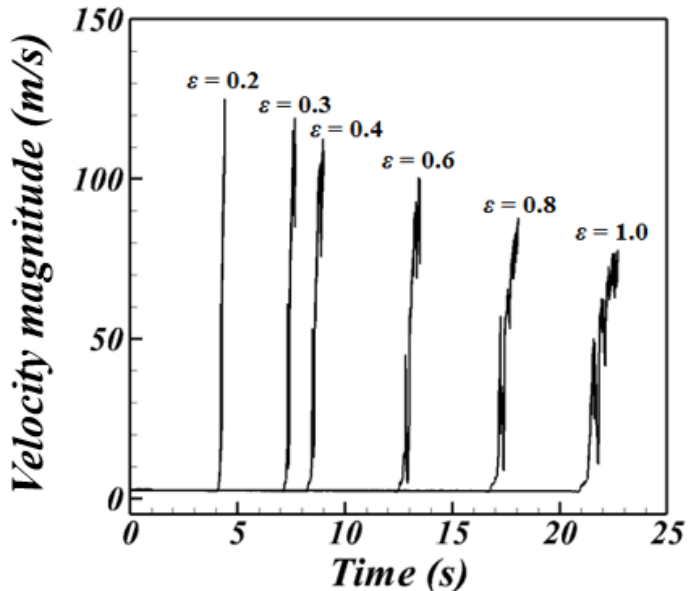

(b)

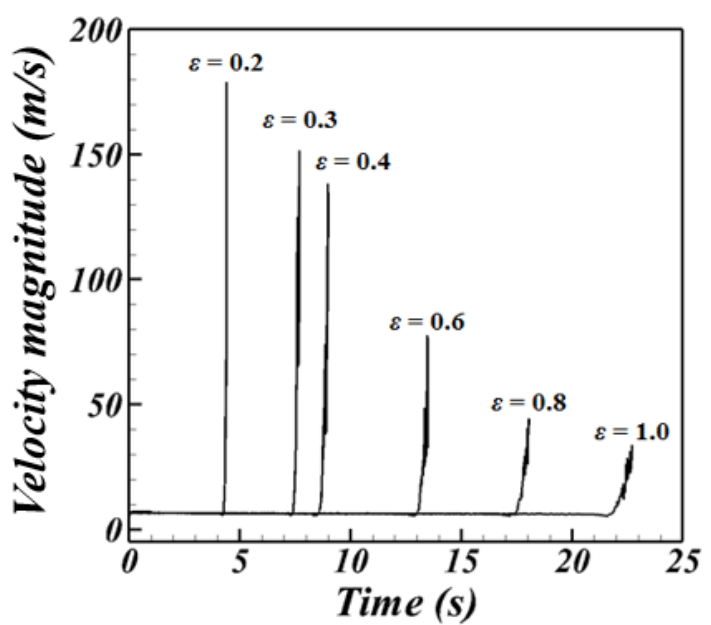

(c)

Figure 14. Time histories of velocity magnitude for five different porosities $(\varepsilon)$ at different probes of (a) A, (b) B, and (c) C marked in Figure 1b.

Due to the drain into the taphole near this region where viscous effect is predominant to the flow, the free surface did not maintain a flat plane; rather, it inclined to the taphole. Regarding the sudden drop of the mass flow rate, the time interval between nearby porosity magnitudes was almost a constant 'value', because this time interval strongly depends on the net volume of the liquid metal initially filled in the tank. The net volume of the 
liquid metal was confined by the porosity magnitude. Therefore, the dimensional gas break breakthrough time was linear with respect to the porosity magnitude.

He et al. [7] used the dimensionless gas breakthrough time, $\tau$, to apply the results to a real system, which is defined as follows:

$$
\tau=\frac{t}{t_{\text {ave }}}=\frac{4 Q t}{\pi D^{2} H}
$$

where $t$ is the dimensional gas breakthrough time which is nondimensionalized by the averaged time $t_{a v g}$ and is the time taken to completely drain the oil at the average draining rate $Q$. In addition, the flow-out coefficient, $F_{L}$, is used for the dimensionless parameter as follows:

$$
F_{L}=180 \frac{(1-\varepsilon)^{2}}{\varepsilon^{3}} \frac{1}{\phi^{2} d^{2}} \frac{\mu}{\rho g} V_{0}\left(\frac{D}{H}\right)^{1.4}
$$

where $\varepsilon$ is packed-bed porosity, $\phi$ is the shape factor of particle ( $\phi=1$ for a sphere), $d$ is the particle diameter, $\mu$ is oil viscosity, $\rho$ is the oil density, $g$ is the gravitational acceleration, and $V_{0}$ is a superficial velocity.

Figure 15 shows the dimensionless gas breakthrough time according to the porosity magnitude. The value of $\tau$ monotonically increases with increasing the porosity magnitude, resulting in a linear relationship with respect to porosity magnitude. This result is consistent with the mean position of the free surface, as shown in Figure 11. Therefore, the dimensionless gas breakthrough time is strongly dependent on the net volume of the liquid initially filled in the tank.

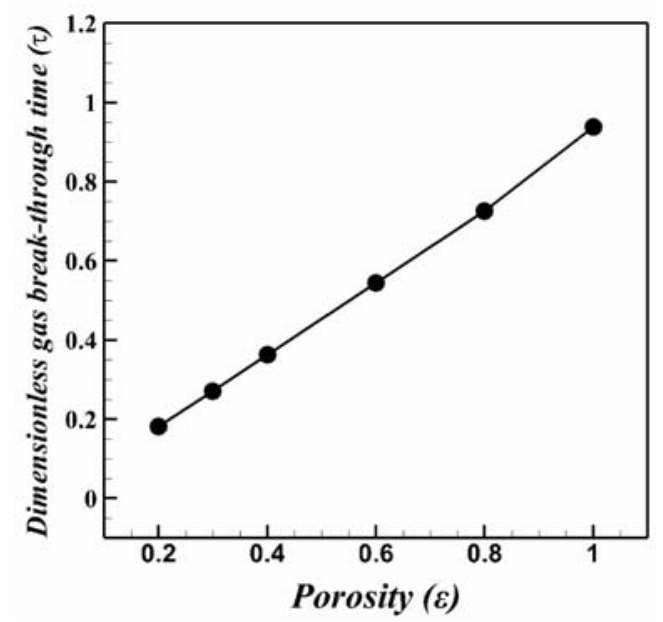

Figure 15. Dimensionless gas breakthrough time $(\tau)$ according to porosity $(\varepsilon)$.

The dimensionless gas breakthrough time according to the flow-out coefficient is presented in Figure 16, which is expected to provide similarities between the laboratory scale and the real scale. The significant variation of $\tau$ occurred for the very small values of $F_{L}$, limited to approximately less than 0.1 . In this narrow range of $F_{L}$, the dimensionless gas breakthrough time rapidly decreased with increasing $F_{L}$. Beyond this region, $\tau$ varied very slightly. 


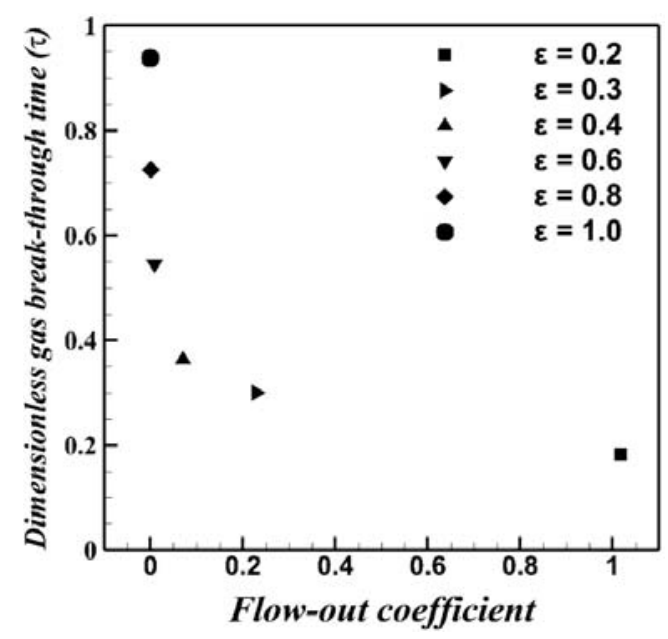

Figure 16. Dimensionless gas breakthrough time $(\tau)$ according to flow-out coefficient.

\section{Conclusions}

The numerical simulations for the two-phase fluids flow in a tank have been performed to understand the effects of gas entrainment into the taphole and the porosity on the deformation of the gas-liquid interface.

The viscous finger formation of the free surface was appeared near the taphole of the tank with porosity. The gas entrainment into taphole disturbed the axi-symmetric formation of the free surface, forming a viscous finger due to interface instability. The viscous finger by the gas entrainment was associated with acceleration of the free surface falling velocity and the outflow near the taphole.

The free surface descended faster with the decreasing porosity magnitude, which helped the gas to drain more rapidly. The sudden drop of the mass flow rate was governed by the gas entrainment into the taphole at the gas break-through time. This dimensionless gas break-through time is linear with respect to the porosity magnitude.

The dimensionless gas break-through time according to the flow-out coefficient is presented to use the similarity between the laboratory scale and the real scale. The significant variation of the dimensionless gas break-through time for the very small values of the flow-out coefficient is limited to less than about 0.1 . In this narrow range of flow-out coefficient, the dimensionless gas break-through time rapidly decreases with increasing the flow-out coefficient. Beyond this region, the flow-out coefficient varies only slightly.

Author Contributions: Supervision, H.-S.Y.; Writing-original draft preparation, H.-S.Y.; Methodology, K.-M.P. All authors have read and agreed to the published version of the manuscript.

Funding: This work was supported by the National Research Foundation of Korea (NRF) grant funded by the Korea government (MSIT) (NRF-2019R1A2C1009081). Additionally, this study was supported by BK21 FOUR Graduate Program for Green-Smart Naval Architecture and Ocean Engineering of Pusan National University.

Institutional Review Board Statement: Not applicable.

Informed Consent Statement: Not applicable.

Data Availability Statement: Not applicable.

Conflicts of Interest: The authors declare no conflict of interest.

\section{References}

1. Kashiwaya, Y.; Kanbe, M.; Ishii, K. Reaction behavior of facing pair between hematite and graphite: A coupling phenomenon of reduction and gasification. ISIJ Int. 2001, 41, 818-826. [CrossRef]

2. Yang, J.; Mori, T.; Kuwabara, M. Mechanism of carbothermic reduction of hematite in hematite-carbon composite pellets. ISIJ Int. 2007, 47, 1394-1400. [CrossRef] 
3. Iwai, Y.; Ishiwata, N.; Murai, R.; Matsuno, H. Control technique of coke rate in shaft furnace by controlling coke reactivity. ISIJ Int. 2016, 56, 1723-1727. [CrossRef]

4. Nemoda, S.; Mladenović, M.; Belošević, S.; Mladenović, R.; Dakić, D. Numerical model of gaseous fuel jet injection into a fluidized furnace. Int. J. Heat Mass Transf. 2009, 52, 3427-3438. [CrossRef]

5. Fu, D.; Tang, G.; Zhao, Y.; D'Alessio, J.; Zhou, C.Q. Modeling of iron ore reactions in blast furnace. Int. J. Heat Mass Transf. 2016, 103, 77-86. [CrossRef]

6. Natsui, S.; Takai, H.; Nashimoto, R.; Kikuchi, T.; Suzuki, R.O. Model study of the effect of particles structure on the heat and mass transfer through the packed bed in ironmaking blast furnace. Int. J. Heat Mass Transf. 2015, 91, 1176-1186. [CrossRef]

7. Reddy, B.V.; Basu, P. A model for heat transfer in a pressurized circulating fluidized bed furnace. Int. J. Heat Mass Transf. 2001, 44, 2877-2887. [CrossRef]

8. Kontogeorgos, D.A.; Keramida, E.P.; Founti, M.A. Assessment of simplified thermal radiation models for engineering calculations in natural gas-fired furnace. Int. J. Heat Mass Transf. 2007, 50, 5260-5268. [CrossRef]

9. Wu, L.; Xu, X.; Zhou, W.; Su, Y.; Li, X. Heat transfer analysis of blast furnace stave. Int. J. Heat Mass Transf. 2008, 51, 2824-2833. [CrossRef]

10. Zhang, Y.; Deshpande, R.; Huang, D.F.; Chaubal, P.; Zhou, C.Q. Numerical analysis of blast furnace hearth inner profile by using CFD and heat transfer model for different time periods. Int. J. Heat Mass Transf. 2008, 51, 186-197. [CrossRef]

11. Steinboeck, A.; Wild, D.; Kiefer, T.; Kugi, A. A mathematical model of a slab reheating furnace with radiative heat transfer and non-participating gaseous media. Int. J. Heat Mass Transf. 2010, 53, 5933-5946. [CrossRef]

12. Jang, J.H.; Lee, D.E.; Kim, M.Y.; Kim, H.G. Investigation of the slab heating characteristics in a reheating furnace with the formation and growth of scale on the slab surface. Int. J. Heat Mass Transf. 2010, 53, 4326-4332. [CrossRef]

13. Johansson, R.; Leckner, B.; Andersson, K.; Johnsson, F. Influence of particle and gas radiation in oxy-fuel combustion. Int. J. Heat Mass Transf. 2013, 65, 143-152. [CrossRef]

14. Courtessole, C.; Etay, J. Flows and mass transfers in two superimposed liquid layers in an induction furnace. Int. J. Heat Mass Transf. 2013, 65, 893-906. [CrossRef]

15. Gu, M.; Chen, G.; Liu, X.; Wu, C.; Chu, H. Numerical simulation of slab heating process in a regenerative walking beam reheating furnace. Int. J. Heat Mass Transf. 2014, 76, 405-410. [CrossRef]

16. Blaszczuk, A.; Nowak, W. Heat transfer behavior inside a furnace chamber of large-scale supercritical CFB reactor. Int. J. Heat Mass Transf. 2015, 87, 464-480. [CrossRef]

17. Han, Y.; Yu, E.; Han, Z. Study on temperature distribution non-uniformity of inner grooved copper tubes during pit furnace annealing. Int. J. Heat Mass Transf. 2017, 104, 749-758. [CrossRef]

18. Su, C.R.; Liu, W.L.; Lai, H.Y. Estimation for inner surface geometry of furnace wall using inverse process combined with grey prediction model. Int. J. Heat Mass Transf. 2009, 52, 3595-3605. [CrossRef]

19. Han, S.H.; Chang, D. Optimum residence time analysis for a walking beam type reheating furnace. Int. J. Heat Mass Transf. 2012, 55, 4079-4087. [CrossRef]

20. Yagi, J. Mathematical modeling of the flow of four fluids in a packed bed. ISIJ Int. 1993, 33, 619-639. [CrossRef]

21. Dong, X.; Yu, A.; Yagi, J.; Zulli, P. Modelling of multiphase flow in a blast furnace: Recent developments and future work. ISIJ Int. 2007, 47, 1553-1570. [CrossRef]

22. Dong, X.F.; Yu, A.B.; Burgess, J.M.; Pinson, D.; Chew, S.; Zulli, P. Modelling of multiphase flow in ironmaking blast furnace. Ind. Eng. Chem. Res. 2009, 48, 214-226. [CrossRef]

23. Zhou, Z.; Zhu, A.; Yu, A.; Zulli, P. Numerical investigation of the transient multiphase flow in an ironmaking blast furnace. ISIJ Int. 2010, 50, 515-523. [CrossRef]

24. Ueda, S.; Natsui, S.; Nogami, H.; Yagi, J.; Ariyama, T. Recent progress and future perspective on mathematical modeling of blast furnace. ISIJ Int. 2010, 50, 914-923. [CrossRef]

25. Ren, W.; Zhao, A.; Jin, N. Void fraction measurement of Oil-Gas-Water three-phase flow using mutually perpendicular Ultrasonic sensor. Sensors 2020, 20, 481. [CrossRef] [PubMed]

26. Ahmed, W.; Fatayerji, A.; Elsaftawy, A.; Hassan, M.; Weaver, D.; Riznic, J. A new capacitance sensor for measuring the void fraction of two-phase flow through tube bundles. Sensors 2020, 20, 2088. [CrossRef] [PubMed]

27. Roshani, M.; Phan, G.; Roshani, G.H.; Hanus, R.; Nazemi, B.; Corniani, E.; Nazemi, E. Combination of X-ray tube and GMDH neural network as a nondestructive and potential technique for measuring characteristics of gas-oil-water three phase flows. Measurement 2021, 168, 108427. [CrossRef]

28. Roshani, M.; Pahn, G.T.T.; Ali, P.J.M.; Roshani, G.H.; Hanus, R.; Duong, T.; Corniani, E.; Nazemi, E.; Kalmoun, E.M. Evaluation of flow pattern recognition and void fraction measurement in two phase flow independent of oil pipeline's scale layer thickness. Alex. Eng. J. 2021, 60, 1955-1966. [CrossRef]

29. Stevenson, P.; He, Q. Slug flow in a blast furnace taphole. Chem. Eng. Proc. 2005, 44, 1094-1097. [CrossRef]

30. He, Q.; Evans, P.; Zulli, P.; Tanzil, F. Cold model study of blast gas discharge from the taphole during the blast furnace hearth drainage. ISIJ Int. 2012, 52, 774-778. [CrossRef]

31. He, Q.; Zulli, P.; Lee, B.; Dunning, J.; Evans, G. Flow characteristics of a blast furnace taphole stream and its effects on trough refractory wear. ISIJ Int. 2002, 42, 235-242. [CrossRef] 
32. He, Q.; Zulli, P.; Evans, G.; Tanzil, F. Free surface instability and gas entrainment during blast furnace drainage. Dev. Chem. Eng. Miner. Proc. 2006, 14, 429. [CrossRef]

33. Saffman, P.G.; Taylor, G.I. The penetration of a fluid into a porous medium or Hele-Shaw cell containing a more viscous liquid. Proc. R. Soc. Lond. A Mat. 1958, 245, 312-329.

34. Hill, S. Channelling in packed columns. Chem. Eng. Sci. 1952, 1, 247-253. [CrossRef]

35. Tabeling, P.; Zocchi, G.; Libchaber, A. An experimental study of the Saffman-Tayloer instability. J. Fluid Mech. 1987, 177, 67-82. [CrossRef]

36. Siemens. STAR-CCM+ User Guide Version 9.04; Siemens: New York, NY, USA, 2011.

37. Launder, B.E.; Spalding, D.B. Lectures in Mathematical Models of Turbulence; Academic Press: New York, NY, USA, $1972 ;$ pp. 157-162.

38. Ergun, S. Fluid flow through packed columns. Chem. Eng. Prog. 1959, 48, 89-94.

39. Huang, H.; Ayoub, J.A. Applicability of the Forchheimer Equation for Non-Darcy Flow in Porous Media. In Proceedings of the SPE Annual Technical Conference and Exhibition, San Antonio, TX, USA, 24-27 September 2006; p. SPE-102715-MS.

40. Hirt, C.W.; Nichols, B.D. Volume of fluid (VOF) method for the dynamics of free boundaries. J. Comput. Phys. 1981, 39, $201-225$. [CrossRef]

41. Shao, L.; Saxen, H. A simulation study of two-liquid flow in the taphole of the blast furnace. ISIJ Int. 2013, 53, 988-994. [CrossRef] 